
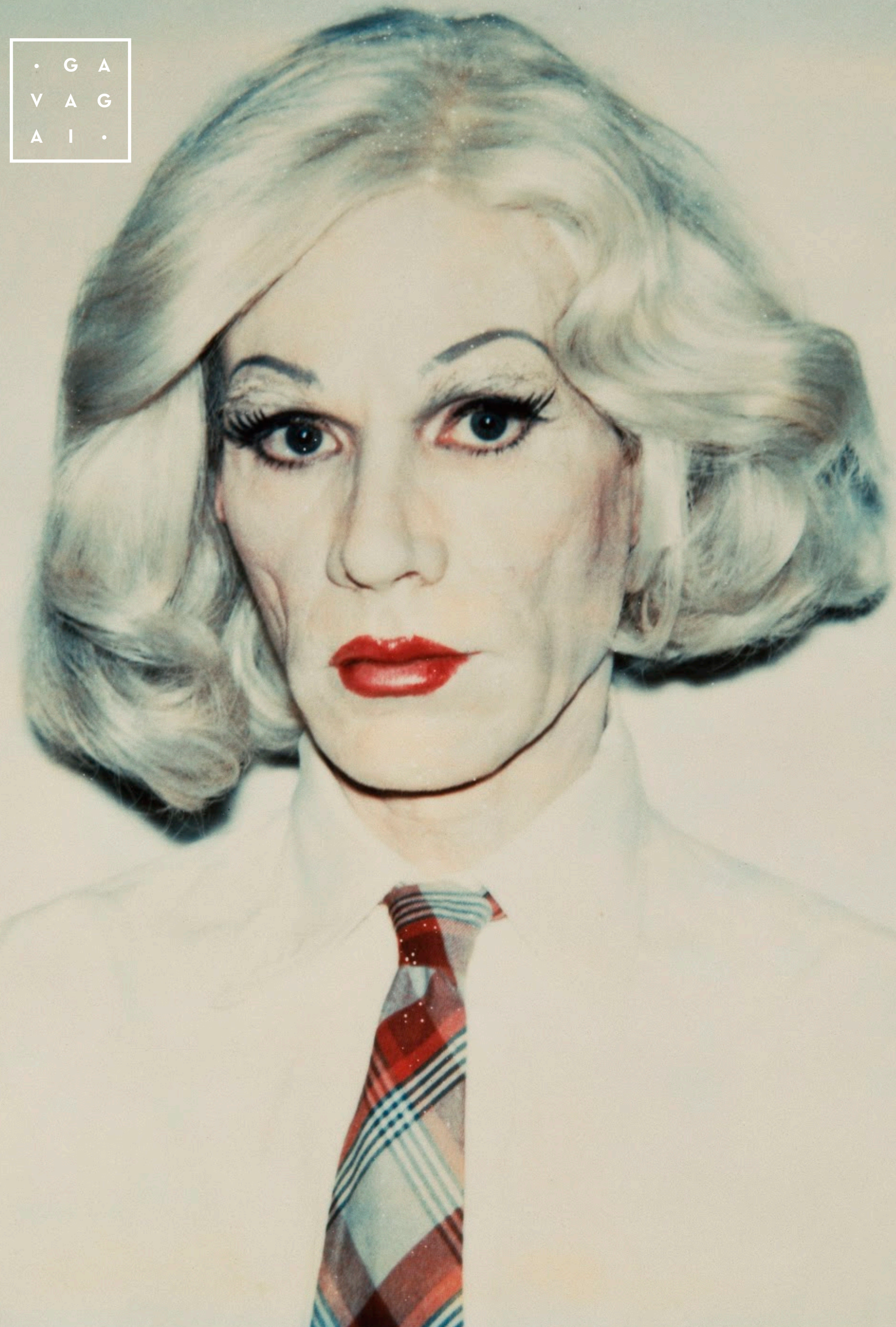


\title{
AS SENTENÇAS \\ RELATIVAS COM NÚCLEO NOMINAL \\ NOS DADOS DE FALA DE \\ PORTO ALEGRE \\ DO PROJETO VARSUL
}

\author{
LAS CLÁUSULAS RELATIVAS CON NÚCLEO EN LOS DATOS DEL HABLA \\ DEL PROYECTO VARSUL DE PORTO ALEGRE
}

THE RELATIVE CLAUSE WITH NOMINAL NUCLEUS IN SPEECH DATA OF

PORTO ALEGRE FROM VARSUL PROJECT

\author{
Rejane Nickel ${ }^{1}$ \\ Elisabete Baú ${ }^{2}$ \\ Ani Carla Marchesan ${ }^{3}$
}

1 Licenciada em Letras. Acadêmica do curso de Mestrado em Estudos Linguísticos da Universidade Federal da Fronteira Sul, Campus Chapecó, PPGEL. E-mail: rejanecnickel@hotmail.com.

2 Licenciada em Letras. Acadêmica do curso de Mestrado em Estudos Linguísticos da Universidade Federal da Fronteira Sul, Campus Chapecó, PPGEL. E-mail: beti.bau@gmail.com. 
RESUMO / RESUMEN / ABSTRACT

RESUMO: Este artigo tem por objetivo analisar, a partir de dados reais de fala de um informante porto alegrense retirados do projeto VARSUL, o uso variável das três estratégias de relativização do PB: relativa padrão, relativa resumptiva e relativa cortadora. As principais questões que pretendemos responder nesta análise são as seguintes: a) Qual construção relativa é mais recorrente?; e b) Como se apresentam os nossos resultados em relação aos de Tarallo $(1983,1993)$ e Valer (2008), que também analisaram dados reais de fala? Esta análise teve como pressuposto teórico o modelo Standard de Chomsky (1977), que afirma que o pronome relativo nasce na posição mais baixa da sentença encaixada e se movimenta para o Spec-CP, conectando essa sentença com a sentença matriz pela correferência do pronome relativo com o pivô (núcleo nominal relativizado). Na análise dos dados, 109 sentenças relativas foram encontradas. A partir da análise, chegou-se a conclusão de que nas sentenças relativas faladas no PB a estratégia mais utilizada é a padrão DP e o pronome relativo mais recorrente é o [que]. Esses resultados corroboram os encontrados por Valer (2008) e mostrou uma pequena mudança em comparação com os dados das relativas PPs encontrados por Tarallo (1983).

Palavras-chave: Estratégias de relativização. Relativas padrão. Relativas resumptivas. Relativas cortadoras. VARSUL

RESUMEN: Este artículo tiene como objetivo analizar, a partir de datos reales del habla de un informante de Porto Alegre quitado del proyecto VARSUL, el uso variable de tres estrategias de relativización del PB: relativa padrão, relativa resumptiva e relativa cortadora. Las principales cuestiones que pretendemos contestar en este análisis son las siguientes: a) ¿Cuál construcción relativa es más frecuente;? y b) ¿Cómo se presentan nuestros resultados en relación con Tarallo $(1983,1993)$ y Valer (2008), que también han analizado los datos reales de habla? Este análisis tiene por apoyo teórico el modelo Standard de Chomsky (1977), que establece que el pronombre relativo nazca en la posición más baja de la oración encajada y se mueve a Spec-CP, conectando esta oración con la matriz por la correferencia del pronombre relativo con el pivô (núcleo nominal relativizado). En el análisis de datos, han encontrado 109 sentencias relativas. A partir del análisis, llegamos a la conclusión de que las cláusulas relativas habladas en el PB la estrategia más utilizada es el padrão DP y el pronombre relativo más recurrente es [que]. Estos resultados corroboran con los encontrados por Valer (2008) y mostraron un cambio en comparación con los datos encontrados por Tarallo (1983) en relación con las cortadoras.

Palabras clave: Estrategias de relativización. Relativas padrão. Relativa resumptiva. Relativa cortadora. VARSUL.

ABSTRACT: This paper aims to analyse, through speech data from a Porto Alegre citizen from VARSUL Project, the use of the three relativization strategies on Brazilian Portuguese: standard, resumptive and chopping. The main questions in this work are a) Which relative construction is the most frequent? and b) How does our results are compared in relation with Tarallo (1983) and Valer (2008), who also analyse real speech data? This analysis came from the Standard theory, from Chomsky (1977), who states that the relative pronoun rise on the lower position of the inserted clause and move to Spec-CP, connecting this clause with the main clause through correference between the relative pronoun and the noun. In the data analysis, 109 relative clauses were found. Through the analysis it is concluded that in Brazilian Portuguese speech relatives the most used strategy is the Standard DP and the most used relative pronoun is [que]. These results concord with Valer (2008) and demonstrate a change if compare to the data from Tarallo (1983) in relation to the chopping relatives.

Keywords: Relativization strategies. Standard relatives. Resumptive relatives. Chopping relatives. VARSUL. 


\section{INTRODUÇÃO}

Sabe-se que qualquer teoria científica tem caráter investigativo. Dentro das Ciências Humanas, mais especificamente da Ciência da Linguagem, utilizaremos a teoria linguística da Gramática Gerativa (cujos estudos têm início no final da década de 50) com o intuito de investigar e tentar evidenciar o conhecimento dos falantes nativos de português brasileiro (PB) sobre as propriedades das sentenças relativas (com núcleo).

Essas relativas têm ganhado espaço nos estudos linguísticos e há muito tem se pesquisado sobre quais são as suas características e quais são as estratégias de relativização (TARALLO, 1983; KATO, 1993; ÁREAS, 2002; DE VRIES, 2002, 2005; VALER, 2008). No PB, o que já se sabe é que elas são sentenças que se encaixam na sentença matriz por meio de um pronome relativo que se refere a um núcleo nominal da sentença matriz. Ou seja, relativa é aquela sentença encaixada, que inclui, em um nível de representação semântica mais elevado, uma categoria vazia (ou um pronome resumptivo), correferente a um pronome relativo, que faz ligação, de alguma maneira, com um elemento da sentença matriz, o núcleo nominal, que chamaremos de pivô ${ }^{4}(D E$ VRIES, 2005, p.4):

(1) a. Lucas falou com a menina [que você viu _ ]. b. Lucas falou com a menina [que você viu ela]. c. Lucas viu a menina [que você falou _e ].

A sentença encaixada, entre colchetes, de (1a), é uma relativa pelo fato de ser iniciada pelo pronome relativo [que $]^{5}$, correferente ao nome [menina]. Além disso, outra característica das relativas é que o pivô [menina] pertence tanto à sentença matriz, fazendo parte do objeto indireto do verbo [falar]; como à sentença encaixada, tendo função de objeto direto do verbo [ver], como se verá detalhadamente na próxima seção. A essa sentença, damos o nome de relativa padrão, pois corresponde ao prescrito pela gramática normativa. Outra opção é como (1b), chamada de relativa resumptiva, porque no lugar do vazio (gerado pelo movimento do pronome relativo para a periferia esquerda da sentença), há um pronome resumptivo [ela], que também retoma o pivô [menina] através do [que]. Por fim, a outra estratégia de relativização é a cortadora, cujo nome se deve ao apagamento da preposição [com], requerida pelo verbo [falar], em (1c).

Neste trabalho, pretendemos analisar, a partir de dados reais de fala de um informante porto alegrense retirados do projeto VARSUL, o uso variável das três estratégias de relativização do PB: relativa

4 Na literatura, o pivô é também conhecido como núcleo nominal, núcleo, pivô etc

5 Ao contrário do Modelo Standard (CHOMSKY, 1977) que estamos utilizando, diremos que o [que] é um pronome relativo para evitar o uso do Operador Nulo. Para mais explicações, remetemos o leitor para as notas 6 e 8 deste artigo.

6 Estamos cientes do fato de haver, na literatura, pelo menos duas propostas distintas para as relativas. O Modelo Padrão ou Standard, de Chomsky (1977), que considera que a relativa é adjunto de um nome; e o Modelo Raising, de Brame (1968) e Kayne padrão (1a), relativa resumptiva (1b) e relativa cortadora (1c). As questões que pretendemos responder nesta análise são as seguintes:

a) Quais estratégias de relativização são verificadas em nossa amostra?

b) Qual construção relativa é mais recorrente em nossa amostra?

c) Como se apresentam os nossos resultados em relação aos de Tarallo $(1983$, 1993) e Valer (2008), que também analisaram dados reais de fala?

Como hipóteses, acreditamos que encontraremos em nossa amostra, assim como Tarallo $(1983,1993)$ e Valer (2008), as três estratégias de relativização, porque são dados de fala que são mais próximos da competência linguística do informante. Além disso, acreditamos que a estratégia de relativização mais recorrente é a padrão DP (conforme 1a) e o pronome relativo mais utilizado o [que], pronome mais recorrente em Valer (2008), já que, na fala, este uso é frequente. Por fim, cremos que os resultados dessa pesquisa irão coincidir com aqueles de pesquisas já feitas, embora estes tenham sido realizados com amostras distintas da nossa.

O trabalho se organiza da seguinte forma. Primeiramente, faremos uma descrição detalhada das sentenças relativas no PB. Logo após, apresentaremos uma breve revisão de literatura dos trabalhos já realizados em dados de fala no PB (TARALLO, 1983; VALER, 2008). Por fim, apresentaremos a metodologia empregada neste trabalho, bem como os resultados encontrados e a análise dos dados e, então, faremos as considerações finais sobre o resultado da análise.

\section{RELATIVAS, O QUE SÃO?}

As relativas são sentenças encaixadas que funcionam como adjunto de um nome ${ }^{6}$ (CHOMSKY, 1977), chamado pivô. Esse pivô, segundo De Vries (2002, p.14), é "[...] semanticamente compartilhado entre as sentenças matriz e relativizada"

(2) a. Comprei o livroi $\left[[\text { do qual }]_{i}\right.$ você falou__ _ $]$. b. Comprei o livroi $\left[[\mathrm{ON}]_{\mathrm{i}}\right.$ que você pediu__ $\left.{ }_{\mathrm{i}}\right]$.

Em (2), [livro] é o pivô que, na sentença matriz, faz parte do objeto direto do verbo [comprar]. Na sentença encaixada, há a categoria vazia (_) que é fruto do movimento da expressão Wh (pronome relativo [qual] mais preposição [de]) em (2a) e do Operador Nulo

(1994), que consideram que a relativa é complemento de um determinante. Neste artigo, não iremos entrar nessa discussão e analisaremos as sentenças pelo Modelo Standard, com algumas alterações que iremos apontando ao longo do artigo. Para mais detalhes sobre esses e outros modelos, remetemos o leitor à Áreas (2002).

7 “[...] the pivot is a constituent semantically shared by the matrix clause and the relative clause". (DE VRIES, 2002, p. 14). 
$(\mathrm{ON})^{8}$, em (2b). A expressão Wh e o ON são correferentes ao pivô e funcionam como objeto indireto do verbo [falar] em (2a) e como objeto direto do verbo [pedir] em (2b).

Além de ser encaixada e ter um constituinte compartilhado com a sentença matriz, De Vries (2002, p. 15) acrescenta uma propriedade que ele considera "essencial" para as relativas: "O papel temático e o papel [função] sintático que o pivô exerce na sentença relativa, são em princípio independentes do papel exercido fora da relativa", como na sentença abaixo:

(3) Anabel conhece a menina [que $_{i} \ldots$ ganhou o concurso].

Em (3), a relativa (que está entre colchetes) contém uma categoria vazia (__), coindexada com o pronome relativo [que] que é correferente ao pivô [menina]. Observe que o pivô contêm função sintática e papel temático independentes: faz parte do DP [a menina], que tem função sintática de objeto direto e papel temático de paciente na sentença matriz; e tem função sintática de sujeito (argumento externo do verbo [ganhar]) e papel temático de agente na encaixada.

Com as características expostas até aqui, fica relativamente mais fácil diferenciar uma relativa de outra sentença encaixada:

(4) a. O rato [que eu assustei _ ] foi embora.

b. Tenho medo (de) [que o rato não vá embora].

Em (4), apesar de ambas as sentenças se encaixarem em um nome, [rato] e [medo], apenas (4a) contém uma relativa, pois há uma categoria vazia coindexada ao pronome [que] que está retomando [rato]. Já em (4b), não há uma categoria vazia e nem é possível inserir um pronome resumptivo que retome um nome da sentença matriz (conforme 1b).

No entanto, apenas as características descritas por De Vries (2002), ser encaixada e ter um constituinte compartilhado com a sentença matriz, não bastam para identificar uma relativa no $\mathrm{PB}$. Do contrário, poderíamos identificar (5), abaixo, como relativa:

(5) João falou [que __i assustou um rato].

Em (5), a sentença encaixada [que assustou um rato] contém uma categoria vazia que é correferente a [João] da sentença matriz. Dessa forma, [João] faz parte da sentença matriz e da sentença encaixada.

8 No Modelo Standard, o [que] é tido como complementizador. Assim, para completar a grade argumental do verbo [pedir], no caso de (2b), um ON é criado. O ON tem a funcão de ficar no lugar do pronome relativo (concordando com o pivô), impedindo a saída dos constituintes de dentro da relativa. Esse ON foi muito criticado por ser algo arbitrário, criado apenas para esses casos. Para resolver esse problema, alguns autores argumentam em favor de o [que] ser um pronome relativo. Sem entrar nessa argumentação, aqui, iremos assumir, ao contrário do Modelo Standard, que o [que] é um pronome relativo.
Apesar disso, a sentença encaixada não é uma relativa; primeiro, por não ser adjunto de um nome; e, segundo, pelo fato de não ser possível dividi-la em duas sentenças simples (5a' e 5a"), como ocorre com a sentença que contém uma relativa em (6) abaixo:

(5) a'. *João falou.

a". João assustou um rato.

(6) a. O rato [que eu assustei _ ] foi embora.

a'. O rato foi embora.

a". Eu assustei o rato.

Para efeitos de interpretação, Marchesan (2008, p.15) afirma que uma relativa pode ser dividida em duas sentenças simples para que, com essa divisão, consigamos recuperar o constituinte compartilhado/relativizado, o pivô [rato]. Essa propriedade revela outra: o pivô, ou a expressão $W h$, deve estar sempre adjacente à relativa:

(7) a. João assistiu ao jogo [Relativa que emocionou as pessoas].

b. A bandeira [Relativa com a qual João torceu] era grande.

Essa adjacência só pode ser "quebrada" se houver um "material interveniente" (intervening material), nos termos de Tarallo (1983, p.80). Esse material interveniente pode ser, segundo os dados de fala de Tarallo: uma ou mais sentenças relativas (8a); algo inserido antes do [que $]^{10}(8 \mathrm{~b})$, como uma sentença subordinada, uma pausa, um falso início de fala etc.; algo inserido dentro da relativa, depois do [que] (8c); ou um NP que esteja dentro de um PP, mas somente o primeiro NP seja considerado o pivô (8d):

$(8)^{11}$ a. Mas se você encontrasse uma mulher que você gostasse muito dela, e que ela gostasse muito de você?? (SP81-1-J-163)

b. O único higiênico que tinha lá era o Garanhão, o único, que ele fez um banheiro para ele de 12 metros quadrados. (SP81-1-11-258)

c. Tinha uma outra que era alemã, que não sei que cargas d'água ela saiu. (SP81-1-A-503)

d. Aí teve um rapaz aqui de Jundiaí que ele levou umas balas sabe? (SP81-1-11-574)

9 "The semantic $\nabla$-role and the syntactic role that the pivot constituent plays in the relative clause, are in principle independent of its role outside the relative." (DE VRIES, 2002, p.15)

10 Tarallo (1983) se refere apenas ao [que] porque ele está se referindo apenas as relativas resumptivas, que só ocorrem com esse tipo de pronome, conforme veremos na seção (3.2)

11 As sentenças de (8) são de Tarallo (1983, p.80). Para melhor visualização, grifamos o pivô e a relativa. 
Observe que os exemplos de Tarallo (1983, p.80) são todos de relativas resumptivas, porque os dados foram retirados do capítulo em que ele trata desse tipo de relativa. Esse "material interveniente" pode ser encontrado em outras estratégias de relativização, como nos casos abaixo (9) retirados dos dados de fala do projeto VARSUL. Importante mencionar que em todos os casos, o "material interveniente" funciona como uma espécie de aposto, mesmo que às vezes não seja transcrito entre vírgulas como quer a gramática normativa.

(9) a. "[...] passava o bonde, essa Rua dos Andrades, que era o Bonde Duque e o Bonde Gasômetro". (RSPOA01MBPRI89-91)

b. "[...] a Caldas Júnior, na parte de cima, que conserva ainda os paralelepípedos [...]" (RSPOA01MBPRI162-164)

Com a inclusão dessas duas características, conseguimos afirmar com mais segurança que a sentença (5) não contém uma relativa: não pode ser divida em duas sentenças simples (conforme 5a' e 5a") e o constituinte "compartilhado" [João] não está adjacente à sentença encaixada - o verbo [falar] é que está adjacente à encaixada - e não se constitui como "material interveniente". Por isso, dizemos que em (5) temos uma simples sentença encaixada que é complemento do verbo [falar].

Em resumo, as seguintes características identificam uma relativa em PB: a) é uma sentença encaixada que funciona como adjunto adnominal; b) contém um constituinte (pivô) compartilhado com a sentença matriz; c) contém um pivô que tem função sintática e papel temático independentes daqueles exercidos na sentença matriz; d) faz parte de uma sentença complexa que pode ser dividida, para efeitos de interpretação, em duas sentenças simples; e e) precisa estar adjacente ao pivô da sentença matriz.

Encaixam-se nessas características, três tipos de relativas que são o foco desse trabalho e que passamos a descrever agora.

\section{TIPOS DE RELATIVAS}

Em $\mathrm{PB}$, as relativas podem ser divididas entre padrão, resumptiva e cortadora (TARALLO, 1983). As relativas padrão se dividem em

\section{Determinante}

13 Preposição

14 As relativas padrão PP também são chamadas de relativsa pied-piping em alusão à obra do escritor inglês Robert Browning (1812-1889), The pied-piper of Hamelin, que conta a história de um flautista (pied-piper) que livrou a aldeia de Hamelin de todos os ratos. "Os ratos eram encantados com o som da flauta [pipe] e seguiam o pied-piper onde quer que ele fosse. A comparação sugere que o DP seja o flautista e a preposição, o rato." (RADFORD, 1997, p. 138 apud ÁREAS, 2002, p. 78).
$\mathrm{DPs}^{12}$ e PPs ${ }^{13}$, assim como as resumptivas. As cortadoras podem apenas ser PP. Essas divisões serão explanadas nas subseções abaixo.

\subsection{RELATIVAS PADRÃO}

As relativas padrão, como mencionado anteriormente, podem ser divididas em duas. Observe as sentenças abaixo:

$$
\begin{aligned}
& \text { (10) a. A peça }\left[[\mathbf{q u e}]_{\mathrm{i}} \text { Anabel assistiu }\left[\mathrm{DP} \_\right]_{\mathrm{i}}\right] \text {. } \\
& \text { b. O batom }\left[[\text { com o qual / com que }]_{i}\right. \text { Carla pintou os }
\end{aligned}
$$

Em (10a), temos uma relativa padrão DP pelo fato de o alvo da relativização ser um DP. Em (10b), o alvo da relativização é um PP (a categoria vazia é um PP correferente ao PP relativizado). Essa relativa, padrão $\mathrm{PP}^{14}$, se caracteriza por conter uma preposição imediatamente antes do pronome relativo. O que acontece em (10b) é que, ao se mover para a periferia esquerda da sentença, o pronome relativo [o qual / que] leva a preposição [com] já que em PB não há preposição órfã, como podemos observar pela agramaticalidade de $(10 c)^{15}$.

Quanto ao pronome relativo, as relativas padrão DP só podem ser introduzidas pelos pronomes [que] e [qual], que equivalem a DPs, como em (11), pois desempenham funções prototípicas de DP. sujeito (11a) e objeto direto (11b):

\section{(11) a. Anabel ouviu histórias sobre a casa [que __caiu] b. Anabel ouviu a música [a qual você compôs__ ].}

[que] e [qual] também podem ser complemento de preposição, mas, nesse caso, a relativa formada será padrão PP, como em (10b) acima.

Os pronomes [quem], [o que] e [quanto], conforme Marchesan (2008), que se baseia nos traços semânticos apresentados em Móia $(1992)^{16}$, são especificados, ou seja, embutem os traços semânticos do pivô $($ quem $=[+$ humano $]$; o que $=[+$ coisa $]$ e quanto $=[+$ quantia $])$ e não conseguem introduzir relativas padrão $\mathrm{DP}$, como mostram as sentenças agramaticais de (12):

\footnotetext{
15 Em PB, há algumas exceções, que merecem estudo, de relativa com preposição órfã. São casos com preposições que têm mais carga lexical, como o [sem] e [contra] (i) Este é o remédio [que Pedro não vive sem (ii) ?Esta é a guerra [que você lutou contra __]. Ao contrário, em inglês, relativas com preposição órfã, chamadas de relativas com preposition stranding, são frequentes: (iii) The person [who Mary talked to__].

16 A análise feita por Móia (1992) e Marchesan (2008) é para as relativas livres, mas se encaixa nas características das relativas com núcleo aqui analisadas.
} 
(12) a. ${ }^{*}$ João viu a menina [quem você falou _ ]

b. *Este panfleto não especifica o propósito [o que ele foi produzido __ ].

c. ${ }^{*}$ Imagine o valor [quanto Anabel vendeu o livro para João__ ].

A explicação para esse fato é que, como o traço semântico do pronome relativo é igual ao do pivô, eles não conseguem ficar adjacentes. Esses três pronomes, que também são DPs (por serem parafraseados por $\underline{a}$ pessoa que, $\underline{a}$ coisa que e $\underline{a}$ quantia que, respectivamente), só conseguem introduzir relativas padrão $\mathrm{PP}$, como em (13):

(13) a. João viu a menina [de quem você falou _ ].

b. Este panfleto não especifica o propósito [para o que ele foi produzido _ $]^{17}$.

c. Imagine o valor [por quanto Anabel vendeu o livro para João__ ].

á os pronomes [quando], [onde] e [como], que embutem os traços semânticos de [+tempo], [+lugar] e [+modo/forma], respectivamente, têm natureza oblíqua, "pois parecem corresponder a sintagmas preposicionados: no dia (em) que, no lugar (em) que e da forma que, respectivamente." (MARCHESAN, 2012, p.35). Ou seja, são talhados para serem adjunto adverbial de quantia, de lugar e de modo, respectivamente. Por isso, esses pronomes (ou advérbios relativos) podem apenas introduzir relativas padrão PP:

(14) a. Adoro o período [quando/em que estou de férias $-]^{18}$.

b. João mora no lugar [onde/em que Pedro nasceu $-]^{19}$.

c. Gosto da forma $\left[\mathbf{c o m o} / \mathbf{q u e} /{ }^{*} \text { em que ela sorri } \_\right]^{20}$.

Observe que a preposição não está explícita, pois os pronomes relativos funcionam como adjunto adverbial e, por isso, podem ser parafraseados por PPs, como vemos ao lado dos pronomes relativos de (14). A exceção é o pronome [como] que, apesar de ser um adjunto adverbial (de modo), parece rejeitar a preposição em (14c). Além disso, o [onde] parece ser o único que aceita uma preposição em casos em que a expressão $W h$ funciona como objeto indireto ${ }^{21}$ :

(15) "Eu cheguei do lugar [de onde tu vieste __]"22.

Apesar de ser uma explicação problemática, como a própria autora afirma, concordamos com Marchesan (2012, p.36) que, nesse caso, parece que "a preposição é cega" ao fato de que o [onde] incorpora uma preposição.

\subsection{RELATIVAS RESUMPTIVAS}

Da mesma forma que a padrão, as sentenças relativas resumptivas podem ser divididas em DP em PP. O nome, resumptiva, se deve ao fato de a relativa conter um pronome (chamado de resumptivo) com traços de gênero, número e pessoa compatíveis com os traços do pivô (o nome relativizado). Além disso, o resumptivo ocupa o mesmo lugar em que deveria estar a categoria vazia:

(16) a. A peça [que Anabel assistiu ela].

b. O batom [que Carla pintou os lábios com ele].

(16a) é a versão resumptiva de (10a). A diferença está no preenchimento da categoria vazia. Veja que o pronome [ela], de (16a), contém os mesmos traços morfossintáticos do pivô [peça]. Por isso, a relativa resumptiva também é conhecida pelo nome de copiadora, pois o pronome, que está onde deveria estar a categoria vazia, copia os traços do pivô da sentença matriz. Já em (16b), temos uma relativa resumptiva $\mathrm{PP}$, pois há a preposição [com] que acompanha o pronome resumptivo [ele] se referindo ao pivô [batom].

Ao observar as sentenças relativas resumptivas, algo relevante vem à tona, já apontado em Valer (2008) e Marchesan (2008):

(17) a. O bebê [do qual ela cuidou _ _ ]

b. ${ }^{*}$ O bebê [o qual ela cuidou dele] está doente.

c. O bebê [que ela cuidou dele].

Ao tentar formar uma relativa resumptiva a partir da relativa padrão PP (17a); o que temos é uma sentença agramatical (17b). Isso ocorre porque em $\mathrm{PB}$, se uma sentença tem pronome resumptivo, ela só pode ser encabeçada pelo [que], como em (17c):

\subsection{RELATIVAS CORTADORAS}

As relativas cortadoras são chamadas assim porque há o apagamento da preposição regida pelo verbo da sentença encaixada:

(18) O batom [que Carla pintou os lábios _ ].

\footnotetext{
17 Sentença adaptada de Marchesan (2012, p.28).

18 Sentença adaptada de Marchesan (2012, p.37)

19 Sentença adaptada de Marchesan (2012, p.36)

20 Sentença adaptada de Móia (1992, p.144)
}

21 Deixaremos para estudos futuros a descrição mais detalhada das relativas encabeçadas pelos pronomes relativos [como] e [onde].

22 Sentença de Valer (2008, p.37) 
A sentença entre colchetes de (18) é chamada de relativa cortadora, pois, ao se mover para a periferia esquerda da sentença, o pronome [que] não levou consigo a preposição [com] - que encabeça o adjunto adverbial de [pintar] - e ela foi apagada.

Dentre os pronomes relativos que podem introduzir relativas cortadoras estão o [que], [qual], [cujo], como em (19); e o [onde] desde que seja antecedido por preposição exigida por um núcleo da sentença encaixada, como em (20):

(19) a. No dia [que choveu__ ] você estava triste. b. A cadeira [a qual você sentou __ ] está quebrada. c. Aquela é a senhora [cuja comida todos gostam __ ].

(20) "Eu cheguei do lugar [onde tu vieste _ _ ]"23. (adaptado de Valer, 2008, p.37)

\section{ESTUDOS SOBRE RELATIVAS EM DADOS DE FALA}

\subsection{TARALLO (1983)}

Fernando Tarallo, em sua tese "Relativization Strategies in Brazilian Portuguese" (Estratégias de Relativização no Português Brasileiro), publicada em 1983, analisou 4329 estratégias de relativização do PB divididas em: 1700 sentenças extraídas de 45 horas de entrevistas gravadas nos meses de dezembro de 1981 e janeiro de $1982 \mathrm{com}$ informantes da área urbana da grande São Paulo ${ }^{24}$; 1050 relativas retiradas de dados de fala da mídia e 1579 estratégias de relativização retiradas de dados diacrônicos.

A opção por informantes de São Paulo, justifica-se, de acordo com o autor, pois esses "[...] compartilham o mesmo sistema sintático com brasileiros de toda parte do país." ${ }^{25}$ (TARALLO, 1983, p. 54).

O linguista, após a análise dos dados, percebeu que há três estratégias de relativização utilizadas no PB: a padrão, a resumptiva e a cortadora. Em resumo, os resultados da pesquisa indicaram que, ao se tratar de relativas PP (padrão PP, resumptiva PP e cortadora), o PB está perdendo a estratégia padrão e a estratégia cortadora está sendo a forma preferida pelos falantes, sobretudo quando a relativização é com complementos e adjuntos preposicionados.

23 Sentença adaptada de Valer (20058, p.37).

24 Tarallo fez entrevistas com 40 informantes de 4 níveis socioeconômicos diferentes (baseado em educação, salário e ocupação): as entrevistas da classe média e classe alta foram feitas com informantes da cidade de São Paulo e as entrevistas com informantes da classe baixa e classe de operários foram feitas com informantes da cidade de São Bernardo do Campo. Por isso, o autor utiliza o temo "A grande São Paulo".

25 "[...] residents of São Paulo share the same syntactic system with Brazilian in all parts of the country." (TARALLO, 1983, p.54)
Sobre as relativas resumptivas, Tarallo chegou à conclusão de que "[...] os falantes de classe baixa favorecem o uso de pronomes resumptivos enquanto a classe média e alta desfavorecem este uso"26 e que "os falantes de classe alta favorecem, em particular, o uso da cortadora PP como uma 'melhor' estratégia social de troca do quase morto pied piped [= relativa padrão PP]." ${ }^{\text {27 }}$ (p. 252-253). A análise dos dados diacrônicos revelou que a estratégia cortadora é o "resultado de uma mudança drástica no sistema pronominal do século XIX."28 (TARALLO, 1983).

\subsection{VALER (2008)}

Salete Valer, em sua dissertação "As sentenças relativas com núcleo nominal nos dados de fala (projeto VARSUL) de Florianópolis", defendida em 2008, analisou vinte e quatro entrevistas de falantes de Florianópolis/SC, que compõem o banco de dados do projeto VARSUL, totalizando 1696 sentenças relativas. Sua análise seguiu o modelo de Chomsky (1977) e chegou ao seguinte resultado: 75\%, ou seja, a maioria das sentenças relativas são DPs, apresentando em todas (1280) o que ela chama de complementizador [que]. Esse complementizador também aparece em relativas PP (padrão, cortadora e resumptiva), somando 345 sentenças. Nas sentenças PP restantes (71), outros pronomes Wh surgem. A linguista, a partir de sua análise, encontrou outro dado importante: a estratégia de relativização mais recorrente, 1.311 das 1.696 sentenças analisadas, é a padrão.

Valer (2008) ainda aponta um dado importante quando se refere às relativas resumptivas:

[...] a retenção do resumptivo [é] um último recurso em contextos semânticos específicos de indefinitude de núcleo nominal ou, em contextos sintáticos em que há uma quantidade de material interveniente entre o núcleo nominal e a posição relativizada. (VALER, 2008, p. 88)

Um exemplo da afirmação de Valer (2008) está abaixo:

(21) Aqui nós viemos num, vamos supor que fosse uma fazenda, né? que era uma área bem grande [que ela toma o<smiles>[CH]CC</smiles>

[fazenda]

26 "[...] that lower-class speakers favor the use of resumptive pronouns, and the middle-class and upper-class speakers disfavor it." (TARALLO, 1983, p.252)

27 "[...] that upper-class speakers in particular favor the use of PP-chopping as the socially 'better' replacement of the dying piedpiped strategy" (TARALLO, 1983, p.253)

28 "The diachronic data analysis situates PP-chopping as the result of a drastic change in the pronominal system in the 19th century." (TARALLO, 1983) 
Pantanal, né?]. (SCFLP05M BPRI679) (VALER, 2008, p. 100)

Em (21), podemos notar que o núcleo nominal [fazenda] está sendo retomado pelo [que]. Mais adiante, o núcleo nominal [fazenda] é novamente lembrado, porém, por haver grande quantidade de palavras entre o núcleo e a posição a ser relativizada, o falante utilizou-se de um pronome resumptivo [ela], após o [que], para que sua sentença tivesse o entendimento garantido, a semelhança do que dissemos na seção 2 com as sentenças em (8).

\section{METODOLOGIA}

O tratamento metodológico deste estudo iniciou com a busca de outros trabalhos já realizados sobre o assunto (TARALLO, 1983, 1993; VALER, 2008; ÁREAS, 2002) e com a seleção do corpus e a coleta dos dados.

O corpus utilizado é do banco de dados do VARSUL (Variação Linguística Urbana na Região Sul do Brasil), que é um projeto em conjunto das Universidades Federais do Rio Grande do Sul (UFRGS), de Santa Cataria (UFSC) e do Paraná (UFPR) e da Universidade Católica do RS (PUCRS) e tem por objetivo descrever a língua portuguesa na fala e escrita da região sul do Brasil (RS, SC e $\mathrm{PR}$ ), seguindo os modelos labovianos.

Nesse estudo, selecionamos uma entrevista, entre as 24 que compõe o banco de dados do RS. O informante dessa entrevista é do sexo masculino, com mais de cinquenta anos de idade e tem educação primária ( $1^{\text {a }}$ até $4^{\text {a }}$ série). Dessa entrevista, foram destacadas todas as ocorrências de relativas (com núcleo) e essas ocorrências foram analisadas seguindo os seguintes critérios:

a) estratégia de relativização (padrão, cortadora ou resumptiva);

b) função sintática do pronome relativo;

c) pronome relativo que ocorre no processo de relativização ([quem], [o que], [quanto], [quando], [onde], [como], [que], [qual] e [cujo]);

d) tipo de preposição que antecede o pronome relativo nas relativas padrão PP e resumptiva PP e a preposição que deveria anteceder o pronome relativo nas relativas cortadoras; e

e) animacidade do pivô ([+humano] ou [-humano]).
É importante salientar que foram analisadas a fala do entrevistado e do entrevistador indistintamente e que alguns dados foram retirados da análise por serem truncados ou pelo fato de o pronome não ser correspondente com a sentença, como este:

(22) "Aqui teve [uma] - uma sorveteria que o prédio ainda existe [...]" (RSPOA01MBPRI 144-145) - (o pronome que deveria ser utilizado é [cujo]).

Os dados encontrados foram dispostos em tabelas (para análise quantitativa), seguidas de comentários qualitativos e comparativos com os trabalhos de Tarallo (1983) e Valer (2008).

\section{RESULTADOS E ANÁLISE DOS DADOS}

A partir da análise do corpus, encontramos 109 dados de sentenças relativas, que foram divididas segundo os três tipos de estratégias de relativização mencionadas anteriormente:

\begin{tabular}{|c|c|c|c|c|c|}
\hline \multicolumn{2}{|c|}{ DP } & \multicolumn{3}{|c|}{ PP } & \multirow{2}{*}{ TOTAL } \\
\hline Padrão & Resumptiva & Padrāo & Resumptiva & Cortadora & \\
\hline 82 & 4 & 5 & 5 & 13 & 109 \\
\hline $75.22 \%$ & $3.66 \%$ & $4.58 \%$ & $4.58 \%$ & $11.92 \%$ & $100 \%$ \\
\hline
\end{tabular}

Como visto na tabela acima, a estratégia relativa padrão é a vitoriosa em termos de frequência ( $79.81 \%$ dos dados), confirmando o resultado da pesquisa de Valer (2008), sendo a padrão DP a mais recorrente $(76,64 \%)$. Dentre as relativas não padrão, destaca-se a estratégia cortadora, com 11,92\% dos casos. Esse resultado também aparece na pesquisa de Tarallo (1983) cujo estudo das relativas preposicionadas (cortadora, padrão $\mathrm{PP}$ e resumptiva $\mathrm{PP}$ ) revelou a estratégia cortadora como a mais recorrente ( 253 casos, $78 \%$, das 324 relativas preposicionadas encontradas).

Encontramos apenas 9 ocorrências de relativa resumptiva. Esse fato talvez se deva à forte estigmatização que esse tipo de estratégia relativa sofre, como já afirmado em Mollica (2006). Merece destaque o fato de que boa parte delas foram produzidas em contextos em que há um "material interveniente" (cf. seção 2) entre o pivô e o pronome relativo:

(23) a. "[...] o abrigo dos bondes, que hoje em dia já não né? O abrigo só está ali por estar”. (RSPOA01MBPRI96-97)

b. “[...] no topo, lá em cima, que a gurizada se juntava pra ir

lá pra cima [...]” (RSPOA01MBPRI202-203) 
Segundo Valer (2008, p. 88), o fato de o pivô estar longe da relativa, faz com que o falante retome esse pivô, na forma de pronome resumptivo, para proporcionar um pleno entendimento da sentença proferida.

Das cinco estratégias padrão PP produzidas pelo informante, destacamos 2, abaixo:

(24) a. "[...] passado por toda a comissão dos serviços públicos, na qual eram líderes [...]” (RSPOA01MBPRI424425)

b. “[...] meu escritório era no mesmo prédio no (em) que ele também tinha um escritório [...]" (RSPOA01MBPRI708-709)

Essa produção é interessante, pois, apesar de o informante ter baixa escolaridade, produziu 5 relativas padrão PP (21.73\%) de um total de 23 estratégias de relativização PP (100\%) - além das 82 relativas padrão DP (94.2\%) de um total de 87 (100\%). A única explicação possível desse fato é a profissão, pois o informante aparenta, pela conversa, ter trabalhado na prefeitura de sua cidade e, talvez, por questões de pressão social da sua profissão produza essa forma padrão.

\subsection{FUNÇÃO SINTÁTICA DO PRONOME RELATIVO}

Os pronomes relativos foram analisados para descobrir qual é a função sintática de cada um deles.

\begin{tabular}{|c|c|c|c|c|c|c|}
\hline & DP & PP & TOTAL & & & \\
\hline & Padrão & Resumptiva & Padrão & $\begin{array}{c}\text { Resumpti } \\
\text { va }\end{array}$ & Cortadora & \\
\hline $\begin{array}{l}\text { Objeto } \\
\text { Direto }\end{array}$ & $23(28.04 \%)$ & $\begin{array}{c}1 \\
(25 \%)\end{array}$ & 0 & 0 & 0 & $\begin{array}{c}24 \\
(22.01 \%)\end{array}$ \\
\hline $\begin{array}{l}\text { Objeto } \\
\text { Indireto }\end{array}$ & 0 & 0 & 0 & 0 & $\begin{array}{c}5 \\
(38.46 \%)\end{array}$ & $\begin{array}{c}5 \\
(4.58 \%)\end{array}$ \\
\hline $\begin{array}{l}\text { Complem } \\
\text { ento de } \\
\text { preposiçã } \\
o(P P)\end{array}$ & 0 & 0 & 0 & 0 & 1 & 0 \\
\hline Sujeito & $\begin{array}{c}59 \\
(71.95 \%)\end{array}$ & $\begin{array}{c}3 \\
(75 \%)\end{array}$ & 0 & 0 & 0 & $\begin{array}{c}61 \\
(55.96 \%)\end{array}$ \\
\hline $\begin{array}{c}\text { Adjunto } \\
\text { Adnomin } \\
\text { al }\end{array}$ & 0 & 0 & 0 & 0 & 0 & 0 \\
\hline $\begin{array}{l}\text { Adjunto } \\
\text { Adverbial }\end{array}$ & 0 & & $\begin{array}{c}2 \\
(40 \%)\end{array}$ & $\begin{array}{c}4 \\
(80 \%)\end{array}$ & $\begin{array}{c}7 \\
(53.84 \%)\end{array}$ & $\begin{array}{c}13 \\
(11.92 \%)\end{array}$ \\
\hline
\end{tabular}

\begin{tabular}{|c|c|c|c|c|c|c|}
\hline $\begin{array}{c}\text { Predicativ } \\
\text { o }\end{array}$ & 0 & 0 & $\begin{array}{c}2 \\
(40 \%)\end{array}$ & $\begin{array}{c}1 \\
(20 \%)\end{array}$ & 0 & $\begin{array}{c}3 \\
(2.75 \%)\end{array}$ \\
\hline $\begin{array}{c}\text { Complem } \\
\text { ento } \\
\text { nominal }\end{array}$ & 0 & 0 & $\begin{array}{c}1 \\
(20 \%)\end{array}$ & 0 & 0 & $\begin{array}{c}1 \\
(0.91 \%)\end{array}$ \\
\hline Total & $\begin{array}{c}82 \\
(75.22 \%)\end{array}$ & $\begin{array}{c}4 \\
(3.66 \%)\end{array}$ & $\begin{array}{c}5 \\
(4.58 \%)\end{array}$ & $\begin{array}{c}5 \\
(4.58 \%)\end{array}$ & $\begin{array}{c}13 \\
(11.92 \%)\end{array}$ & $\begin{array}{c}109 \\
(100 \%)\end{array}$ \\
\hline
\end{tabular}

Como já era esperado, a maior parte das expressões Wh responsáveis pela relativização têm a função sintática de sujeito, 62 casos (55.96\%); o que vai ao encontro dos dados encontrados por Valer (2008) que encontrou 890 (equivalente a 89\%) dessa mesma estratégia nos dados do VARSUL de Florianópolis. Em segundo lugar, está a função sintática de objeto direto, 24 sentenças, perfazendo $22.01 \%$ dos dados de fala do informante de POA. Esse dado também reforça o encontrado por Valer (2008) que encontrou 374 ocorrências, equivalente a $97 \%$.

Nas relativas PP, a que mais encontramos foi a cortadora, somando 13 sentenças (56.52\%) das 23 relativas PP encontradas (21.10\% dos casos). Dentre essas, a função sintática mais recorrente foi adjunto adverbial, 7, totalizando mais da metade (53.84\%) de cortadoras PP. Em segundo lugar, o objeto indireto, 5 (38.46\%) das cortadoras.

Tarallo (1983) analisa somente sentenças PPs das quais encontrou, nas resumptivas, um maior número de função sintática de sujeito, representando $(10,4 \%)$ dos casos. A segunda função mais recorrente é de objeto indireto ( 16 casos, $21,1 \%$ ).

6.2 pronome relativo que ocorre no processo de relativização.

Em relação ao pronome relativo e/ou expressão Wh utilizado no processo de relativização, chegamos ao seguinte resultado:

Tabela 3: Os pronomes relativos e expressões Wh que ocorrem no processo

\begin{tabular}{c|c|c|c|c} 
& \multicolumn{4}{|c}{ de relativização } \\
& Padrão & Resumptiva & Cortadora & TOTAL \\
\hline Que & $82(80.4 \%)$ & $9(8.65 \%)$ & $13(12.5 \%)$ & $104(95.41 \%)$ \\
\hline PP + que & 0 & 0 & 0 & 0 \\
\hline PP + qual & $1(100 \%)$ & 0 & 0 & $1(0.91 \%)$ \\
\hline Como & 0 & 0 & 0 & 0 \\
\hline Onde & $3(100 \%)$ & 0 & 0 & $3(2.75 \%)$ \\
\hline Quando & $1(100 \%)$ & 0 & 0 & $1(0.91 \%)$ \\
\hline Quem & 0 & 0 & 0 & 0 \\
\hline TOTAL & $87(79.81 \%)$ & $9(8.25 \%)$ & $13(11.92 \%)$ & $109(100 \%)$ \\
\hline
\end{tabular}


Como visto acima, o pronome relativo mais utilizado foi o [que], sendo que $80 \%$ (82) das sentenças que utilizam este pronome são relativas padrão; $8.65 \%$ (9) resumptivas ${ }^{29}$ e $12.5 \%$ (13) cortadoras. Este resultado ocorreu porque, na fala, o uso deste pronome em grande quantidade é comum, conforme já relatado por Valer (2008).

Nos dados de Valer (2008), o maior número de sentenças relativas também foi com o pronome relativo [que], sendo 95\% das relativas padrão, $100 \%$ das resumptivas e $100 \%$ das cortadoras.

A partir desta comparação, podemos ratificar a afirmação feita por Valer (2008) de que, na fala, o pronome relativo mais recorrente é o [que] precedido de preposição ou não. Uma hipótese para essa afirmação pode ser o fato de que ao utilizar a fala, os indivíduos tendam a unificar o pronome relativo, para não deixar a conversa muito formal e para evitar o pedantismo em uma conversa com pessoas de escolaridades diferentes.

Da mesma forma, Tarallo (1983) encontrou a ocorrência de 1681 (98.9\%) de sentenças relativas encabeçadas pelo item [que], que o autor chama de complementizador.

\subsection{TIPO DE PREPOSIÇÃO QUE ANTECEDE O PRONOME RELATIVO}

Nos dados de fala analisados, correlacionamos a preposição (que antecede o pronome relativo das relativas padrão PP e das resumptivas PP e as preposições que poderiam anteceder as relativas cortadora) com a estratégia de relativização:

Tabela 4: preposição que antecede o pronome relativo em relativas PP.

\begin{tabular}{c|c|c|c|c} 
& Padrão PP & Resumptiva PP & Cortadora PP & TOTAL \\
\hline De (os) & 0 & 0 & $4(100 \%)$ & $4(17.39 \%)$ \\
\hline Em (a, o) & $5(26.31 \%)$ & $5(26.31 \%)$ & $9(47.36 \%)$ & $19(82.60 \%)$ \\
\hline TOTAL & $5(21.73 \%)$ & $5(21.73 \%)$ & $13(56.52 \%)$ & $23(100 \%)$
\end{tabular}

A tabela acima não revelou nenhum contexto que favoreça uma ou outra estratégia de relativização. Os dados tiveram resultados muitos próximos. Se destaca a preposição [em] que foi a mais utilizada, nas cortadoras, ou com a maior intensão de ser utilizada, alcançando cerca de $47.36 \%$ (8) das 23 sentenças relativas PP. É importante notar que nas sentenças padrão e resumptiva, a única preposição utilizada foi o [em]. Podemos inferir, a partir deste aspecto, o fato de que isso ocorra porque a maioria destes pronomes relativos e suas preposições estão na sentença como adjunto adverbial, que são em sua maioria precedidos de preposição, o que faz o falante utilizar as palavras [neste], [ali], [aqui], para indicar lugar, tempo, modo, que são retomados nas relativas padrão pelo pronome relativo e nas resumptivas pelo pronome lembrete. Valer (2008) afirma que a preposição [de] aparece em sentenças resumptivas quando o DP é explícito na posição em que é gerado.

\subsection{ANIMACIDADE DO PIVÔ.}

Alguns pronomes relativos, como já mencionado, são especificados, ou seja, têm traços semânticos que exigem que o pivô tenha traços semânticos semelhantes:

\section{(25) a. ${ }^{\star} \mathrm{O}$ [sanduíche] de quem você gosta. b. O [rapaz] de quem você gosta.}

Em (25a) temos uma sentença agramatical pelo fato de o pronome relativo [quem] ter o traço [+humano], colocando assim restrições para o pivô que o antecede, excluindo assim o pivô [sanduíche] que tem o traço semântico [-humano]. A questão é inversa em (25b), em que o pivô [rapaz] tem o traço requerido pelo pronome [quem], [+humano].

Pensando nisso, controlamos os traços [+/- humano] dos pivôs utilizados nos dados em análise para tentar descobrir se há alguma influência disso na escolha por uma outra estratégia de relativização:

\begin{tabular}{c|c|c|c|c|c|c}
\multirow{2}{*}{$\begin{array}{c}\text { Animacidade } \\
\text { do pivô }\end{array}$} & \multicolumn{2}{|c|}{ DP } & \multicolumn{3}{c|}{ PP } & \multirow{2}{*}{ TOTAL } \\
\cline { 2 - 6 } & Padrão & Resumptiva & Padrão & Resumptiva & Cortadora & \\
\hline [+humano] & $23(92 \%)$ & 0 & $1(4 \%)$ & 0 & $1(4 \%)$ & $\begin{array}{c}25 \\
(22.93 \%)\end{array}$ \\
\hline [-humano] & $\begin{array}{c}59 \\
(70.23 \%)\end{array}$ & $4(4.76 \%)$ & $\begin{array}{c}4 \\
(4.76 \%)\end{array}$ & $5(5.95 \%)$ & $\begin{array}{c}12 \\
(14.28 \%)\end{array}$ & $\begin{array}{c}84 \\
(77.03 \%)\end{array}$ \\
\hline TOTAL & $\begin{array}{c}82 \\
(75.22 \%)\end{array}$ & $4(3.66 \%)$ & $\begin{array}{c}5 \\
(4.58 \%)\end{array}$ & $5(4.58 \%)$ & $\begin{array}{c}13 \\
(11.92 \%)\end{array}$ & $\begin{array}{c}109 \\
(100 \%)\end{array}$
\end{tabular}

Analisando os dados da tabela 5, acima, podemos notar que o traço [-humano] pode estar gerando um contexto de favorecimento da relativa padrão DP (70.23\%). Esse traço semântico, de fato, ocorre em $77.03 \%$ das estratégias de relativização.

É importante notar que $82 \%$ destes pivôs [+/- humano] foram utilizados em sentenças padrão DP, o que nos deixa afirmar que, na fala, para se referir às pessoas, os indivíduos utilizam a relativa padrão DP, por, talvez, não haver preposição entre o pivô e o pronome, o que deixa a referência de um [pivô] com outro [pronome] mais evidente, facilitando a referência dada ao pivô.

Na pesquisa de Tarallo (1983), o autor percebeu maior ocorrência de traço semântico [+ humano]. Ainda, o autor afirma que a

29 Importante lembrar que não é possível utilizar outro pronome relativo senão [que] nas relativas resumptivas (cf. seção 3.2 ). 
ocorrência de relativas resumptivas são favorecidas quando a sentença apresentar os traços [+ humano], [+ indefinido] e [+ singular]. Valer (2008) não aborda esse aspecto em sua análise.

\subsection{ESTUDO DIACRÔNICO DAS RELATIVAS PP}

Outro ponto que merece destaque neste artigo é um estudo diacrônico feito por Tarallo (1993), que mostra o uso das estratégias de relativização PP (padrão, resumptiva e cortadora) através dos anos. Tomamos a liberdade de complementar esta tabela utilizando os dados de Valer (2008) e os dados deste artigo:

Tabela 6: Dados sobre o uso de relativas PP na fala apresentados de forma diacrônica.

\begin{tabular}{|c|c|c|c|c|c|c|}
\hline $\begin{array}{l}\text { Ano em que } \\
\text { os dados } \\
\text { foram } \\
\text { coletados }\end{array}$ & $\begin{array}{c}\text { Tarallo } \\
\text { (1993) } \\
\text { Dados do } \\
\text { ano de } \\
1725\end{array}$ & $\begin{array}{c}\text { Tarallo } \\
(1993) \\
\text { Dados do } \\
\text { ano de } \\
1775\end{array}$ & $\begin{array}{c}\text { Tarallo } \\
\text { (1993) } \\
\text { Dados do } \\
\text { ano } \\
\text { del } 825\end{array}$ & $\begin{array}{c}\text { Tarallo } \\
(1993) \\
\text { Dados do } \\
\text { ano de } \\
1880\end{array}$ & $\begin{array}{l}\text { Valer (2008) } \\
\text { Dados do } \\
\text { ano de 1990- } \\
1991\end{array}$ & $\begin{array}{c}\text { Dados deste } \\
\text { artigo - do } \\
\text { ano de } 1993\end{array}$ \\
\hline Padrão & $\begin{array}{c}99 \\
(89.18 \%)\end{array}$ & $\begin{array}{c}89 \\
(88.11 \%)\end{array}$ & $\begin{array}{c}73 \\
(91.25 \%)\end{array}$ & $\begin{array}{c}63 \\
(35.39 \%)\end{array}$ & $\begin{array}{c}71 \\
(16 \%)\end{array}$ & $\begin{array}{c}5 \\
(21.73 \%)\end{array}$ \\
\hline Resumptiva & $11(9.90 \%)$ & $\begin{array}{c}8 \\
(7.92 \%)\end{array}$ & $\begin{array}{c}1 \\
(1.25 \%)\end{array}$ & $\begin{array}{c}9 \\
(5.05 \%)\end{array}$ & $\begin{array}{c}19 \\
(4.6 \%)\end{array}$ & $\begin{array}{c}5 \\
(21.73 \%)\end{array}$ \\
\hline Cortadora & $1(0.90 \%)$ & $\begin{array}{c}4 \\
(3.96 \%)\end{array}$ & $\begin{array}{c}6 \\
(7.5 \%)\end{array}$ & $\begin{array}{c}106 \\
(59.55 \%)\end{array}$ & $\begin{array}{c}326 \\
(78,4 \%)\end{array}$ & $\begin{array}{c}13 \\
(56.52 \%)\end{array}$ \\
\hline TOTAL & $\begin{array}{c}111 \\
(100 \%)\end{array}$ & $\begin{array}{c}101 \\
(100 \%)\end{array}$ & $\begin{array}{c}80 \\
(100 \%)\end{array}$ & $\begin{array}{c}178 \\
(100 \%)\end{array}$ & $\begin{array}{c}416 \\
(100 \%)\end{array}$ & $\begin{array}{c}23 \\
(100 \%)\end{array}$ \\
\hline
\end{tabular}

Fonte: Tarallo (1993, p. 209) e Valer (2008, p.100).

Com a tabela acima, podemos notar que, na análise de Tarallo, as sentenças padrão PP estavam sendo extintas ao longo dos anos, e, no lugar, os falantes estavam utilizando a cortadora. Esse fato se comprova com os dados do VARSUL dos anos 1990-1991, utilizados por Valer (2008), que mostram que a maior parte das sentenças relativas PP analisadas foi do tipo cortadora (78.4\%). O mesmo ocorre com os dados deste artigo, cujos dados foram coletados em 1993, dos quais 13 das 23 sentenças relativas PP são cortadora, somando $54.54 \%$ dos dados.

Para ficar mais claro, observe o gráfico abaixo:

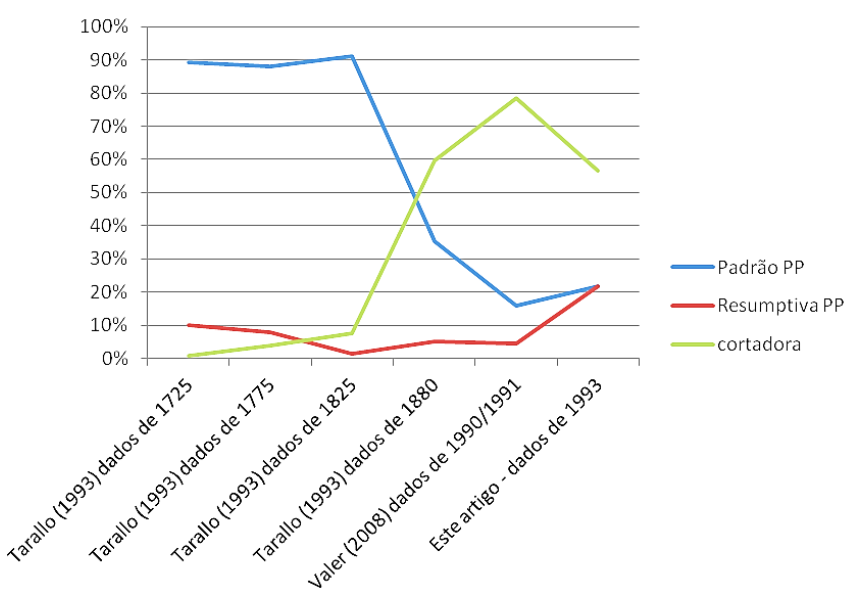

Fonte: Tarallo (1993) e Valer (2008)

Ao observar o desenho da tabela, podemos notar que, ao chegar nos dados deste artigo, a linha das relativas cortadoras decai um pouco e a linha das relativas padrão sobe. Isso provavelmente ocorre pelo fato de termos poucos dados em análise e/ou pelo fato de o informante, apesar de pouco escolarizado, frequentar ambientes em que a forma padrão seja bastante utilizada.

\section{CONSIDERAÇÕES FINAIS}

Neste artigo, objetivamos analisar, a partir dos dados de fala de um indivíduo retirados do projeto VARSUL, o uso de três estratégias de relativização do PB: padrão DP e PP, resumptiva DP e PP e cortadora, e responder quais destas estratégias foram encontradas em nossa amostra, qual é a mais recorrente, e, para finalizar, comparar os resultados com os trabalhos de Tarallo (1983) e Valer (2008)

Em linhas gerais, vimos que uma relativa é uma sentença encaixada que possui um constituinte chamado pivô que é compartilhado com a sentença matriz.

Na sequência, a partir da análise dos dados de fala de um informante do projeto VARSUL de POA, encontramos três tipos de estratégias de relativização: padrão, cortadora e resumptiva.

Descobrimos, na análise, que a construção relativa mais recorrente foi a padrão, com $81.30 \%$ (76.64\% padrão $\mathrm{DP}, 4.67 \%$ padrão $\mathrm{PP})$ das sentenças analisadas neste artigo (cf. tabela 1).

Ao compararmos os resultados obtidos com o de Tarallo (1983), em especial seu estudo diacrônico (1993) em relativas PP, verificamos que, à semelhança do que foi verificado pelo autor, que encontrou em maior número cortadoras dentre as estratégias de relativização PP (padrão, cortadora e resumptiva), o tipo de relativa mais recorrente em nosso corpus também foi a relativa cortadora. Sendo assim, nossa hipótese de que nossos dados iriam corroborar as pesquisas já feitas, se confirmou. 
Em comparação com o trabalho de Valer (2008), encontramos o mesmo resultado quanto ao tipo de estratégia utilizada em $\mathrm{PB}$, na fala, corroborando nossa hipótese inicial. Para as duas análises, a relativa padrão foi a mais recorrente. Outro aspecto que Valer (2008) apontou e que foi corroborado neste artigo foi a maior frequência de uso de pronomes resumptivos, quando há um material interveniente entre a sentença matriz e a relativizada (cf. exemplo 9).

Por fim, ao analisar a animacidade do pivô relativizado, chegamos à constatação de que para pivôs [+humanos] o falante utiliza a relativa padrão DP.

\section{REFERÊNCIAS}

ÁREAS, Eduardo Kenedy Nunes. Aspectos estruturais da relativização em português: uma análise baseada no modelo Raising. 2002. 146f. Dissertação (Mestrado em Linguística) - Programa de Pós-graduação em Teoria em análise linguística, Universidade Federal do Rio de Janeiro, Rio de Janeiro, 2002.

DE VRIES, Mark. The Fall and Rise of Universals on Relativization. University of Groningen, January 2005. Disponível em: <http://odur.let.rug.nl/dvries/pdf/2005-rc-universals-jul.pdf>. Acesso em: 3 ago. 2014.

DE VRIES, Mark. The Syntax of Relativization. 2002. 477f. Tese (Doutorado em Filosofia) - Universidade de Amsterdam, Amsterdam, 2002.

KATO, Mary A. Recontando a história das relativas em uma perspectiva paramétrica. In: ROBERTS, Ian; KATO, Mary A. (Org.). Português brasileiro: uma viagem diacrônica: homenagem a Fernando Tarallo. Campinas, SP: Editora da Unicamp, 1993. p. 223-261

MARCHESAN, Ani Carla. As relativas livres em português brasileiro e os requerimentos de compatibilidade. 2008. 98 f. Dissertação (Mestrado em Linguística) - Programa de Pós-graduação em Linguística, Universidade Federal de Santa Catarina, Florianópolis, 2008.

. As relativas livres no português brasileiro. 2012. 227f. Tese (Doutorado em Linguística) - Programa de Pós-graduação em Linguística, Universidade Federal de Santa Catarina, Florianópolis, 2012.

MOLLICA, Maria Cecilia. Sobre os processos sintáticos que migram da fala para a escrita. In: HISPANIC LINGUÍSTICS SYMPSIUM, 8th., 2006, Somerville, MA. Proceedings... Somerville: Cascadilla Proceedings Project, 2006. p. 167-171.
PROJETO VARIAÇÃO LINGUÍSTICA URBANA NA REGIÃO SUL DO BRAIL (VARSUL). Porto Alegre, Florianópolis, Paraná: UFRGS, PUC-RS, UFSC, UFPR. Disponível em: $<$ http://www.varsul.org.br/>. Acesso em: 28 jun. 2014

TARALlO, Fernando. Relativization Strategies in Brazilian Portuguese. 1983. 273f. Tese (Doutorado em Filosofia), Universidade da Pensilvânia, Pensilvânia, 1983.

TARALLO, Fernando. Diagnosticando uma gramática brasileira: o português daquém e dálem-mar ao final do século XIX. In: ROBERTS, L; KATO, M. A. (Org.). Português brasileiro: uma viagem diacrônica. 2 ed. Campinas: Editora da UNICAMP, 1993. p. 69-106.

VALER, Salete. As sentenças relativas com núcleo nominal nos dados de fala (projeto Varsul) de Florianópolis. 2008. 218f. Dissertação (Mestrado em Linguística) - Programa de Pós-graduação em Linguística, Universidade Federal de Santa Catarina, Florianópolis, 2008. 